\title{
APONTAMENTOS PARA A QUESTÃO DE MÉTODO EM CRÍTICA CULTURAL
}

\author{
Vagner Santos (Pós-Crítica/UNEB)
}

RESUMO: Localiza o Programa de Pós-Graduação em Crítica Cultural da Universidade do Estado da Bahia (Pós-Crítica) no âmbito dos Estudos Culturais brasileiros. Identifica suas filiações teóricas e contextualiza-as na contemporaneidade da região na qual se insere. A partir do curso da disciplina Metodologia em Crítica Cultural, traça apontamentos que busquem uma orientação para a questão do método em sua prática investigativa de crítica cultural. Defende um método de pesquisa intervencionista em relação aos sujeitos-objetos selecionados e transformador da realidade.

Desde a década de 1950 se estabelece uma nova área de estudo que se faz conhecer como Estudos Culturais, tanto na Inglaterra como, posteriormente, nos Estados Unidos.

A desinência "estudos" não é por acaso. A nomenclatura do novo campo poderia partir do tradicional "logia", mas não o faz. Há nisso um gesto de não continuísmo, se assim podemos dizer. Em lugar de uma "culturologia" temos os Estudos Culturais. Parece-me que depois de dois séculos e meio de "logias" os pioneiros dos Estudos Culturais perceberam a cilada em que se meteriam caso tentassem apreender seu objeto, a cultura, com um sistema fechado de conceitos e a eleição de uma única e fixa filosofia de defesa e descrição do mundo ao qual pertence. Entre os vários motivos óbvios ligados a este objeto que justificam tal atitude, mencionemos apenas sua fluidez, sua dinâmica aleatória, sua heterogeneidade (mesmo num grupo homogêneo, se é que existe algum) e sua natureza extremamente subjetiva. Daí que seu corpus teórico depende em muito das conjunturas nas quais a atividade se insere.

Percebe-se que nos distanciamos de qualquer coisa parecida com ciência, ou, no mínimo, do conceito tradicional de ciência. Institucionalmente abre-se um paradoxo: como afirmar uma nova área na academia se esta não é ciência? É preciso voltar um pouco. Toda ciência possui uma filosofia que lhe explica e lhe justifica no mundo, um problema nesse mundo que ela irá resolver, um objeto que traduz este problema e um conjunto fixo de métodos para abordar este objeto. 
Nesses termos, podemos mencionar como filosofia válida o materialismo histórico-dialético proposto por Karl Marx (1983; 1985; 1989; 2004), uma vez que, como diz Sartre (2002), uma filosofia é filha de seu tempo, "é o húmus de todo o pensamento particular e o horizonte de toda a cultura" e não deve ser considerada superada "enquanto o momento histórico de que [é] a expressão não tiver sido superado" (p. 21) - e tenho certeza que as condições históricas sobre as quais se erguem o pensamento de Marx sofreram mudanças, no entanto não foram superadas. Nesse sentido, tendo a dizer que o problema dos Estudos Culturais é o problema de toda ordem de "subalternos", de "marginais", de emergentes, de descolonizados - é, então, os Estudos Culturais, uma sub-filosofia dos oprimidos? Não. Antes, uma ferramenta, uma estratégia, um novo utensílio teórico de tradução das condições de existência do contemporâneo. Seu objeto é justamente, por um lado, as novas condições locais e globais em que se realizam a dominação, a homogeneização e a alienação e, por outro, as novas estratégias de combate a esta tríade colonizadora do capitalismo no nosso século.

Sem precisar remontar a uma genealogia que chega a Sérgio Buarque de Holanda e Gilberto Freyre, basta-nos dizer que os Estudos Culturais no Brasil adensam-se desde a década de 1980 e somente na última década é que a enorme maioria dos poucos cursos de pós-graduação stricto sensu em cultura do país começou a funcionar. E uma vez abordadas suas problemáticas de formação institucional, paramos em um ponto que nos traz à realidade local: a questão do método nos Estudos Culturais brasileiros nesse início de século.

Se os Estudos Culturais possuem uma filosofia, um problema e um objeto (e parece que nunca no singular), falta elaborar seu método, ou melhor, o pano de fundo de seus métodos, sua metodologia, sua teoria do método - uma vez que os procedimentos metodológicos de pesquisa são orientados pela natureza, objeto e objetivos específicos de cada pesquisa. Uma vez que notamos uma variedade teórica a depender do território de estudo e pesquisa cultural, nota-se semelhante variedade no que diz respeito como cada grupo (às vezes, como cada pesquisador) difere em suas reflexões sobre método em Estudos Culturais. Se a questão teórica é, ainda, uma questão aberta nos EC em todo o mundo, não é diferente em relação ao método, uma vez que o método prescinde da teoria e vice-versa. A questão é trazida por cada novo curso de Pós-Graduação stricto 
sensu inaugurado no Brasil, a exemplo do Programa de Pós-Graduação em Crítica Cultural da UNEB, o nono do país.

O Pós-Crítica, no contexto de uma cidade de 155 anos com papel de pequena metrópole para as cidades vizinhas - apesar de manter algumas relações na condição de satélite da capital Salvador -, endossa um discurso comunitário ao mostrar como preocupação a "institucionalização da malha cultural no mundo contemporâneo". Como o próprio nome indica, se filia a uma tradição de "crítica" (Crítica Social, Teoria Crítica) que se diferencia do trabalho puramente teórico e especulativo que tem marcado a ciência tradicional. Tenhamos de antemão o conhecimento, através de sua bibliografia para as duas primeiras seleções para alunos regulares, de que o corpus teórico obrigatório para as três linhas do programa volta-se principalmente a um grande pioneiro dos EC, Stuart Hall - e lembremos que no capítulo "Estudos culturais e seu legado teórico", em Da diáspora, Hall (2003) relata a experiência dos EC britânicos como seguidores do conceito de intelectual orgânico de Antonio Gramsci (1991), ou seja, aliados a movimentos sociais emergentes. Podemos apontar que, de uma maneira geral, os EC, tendo nascido no contexto global de descolonizações, priorizam o heterogêneo, o "dominado", o descolonizado, o silenciado, as insurgências que causam fissuras, as próprias fissuras, os atores "menores", os jogos de dominação e hegemonia e de homogeneização. Sendo assim, os EC andam de mãos dadas com diferenças, com "outras formas" - de subjetivar, de produzir, de objetivar, de enunciar, de sentir, de experimentar.

Se nossa experiência se aproxima da experiência britânica, os EC brasileiros marcam-se pela heterogeneidade de contextos e, por isso, de discursos, de trabalhos, de metodologia e de posicionamentos teóricos diferentes - o Pós-Crítica tendo o seu próprio contexto. Dessa forma, os EC brasileiros e o Pós-Crítica não constituem uma área de regulamentação disciplinar ou "uma grande narrativa ou um meta-discurso de qualquer espécie", consiste, antes, "num projeto aberto ao desconhecido, ao que não se consegue ainda nomear" (HALL, 2003: 199-202).

Entretanto, voltamos à questão da afirmação e legitimação discursiva dos EC brasileiros e do Pós-Crítica. Não podendo abrir mão desse espaço, ambos atendem a outro lado dos EC apontado por Hall a partir da experiência britânica: os EC não são um 
pluralismo simplista em que basta o sujeito localizar sua pesquisa no conjunto, são um projeto sério e político. Por isso, "É importante chegar a uma definição dos estudos culturais". Pois "uma prática que tenta fazer diferença no mundo" deve "marcar pontos de diferença ou distinção a definir e defender". "Trata-se de posicionamentos" que não são nem finais nem absolutos, mudam de lugar de uma conjuntura para outra (HALL, 2003: 199-202). Para Stuart Hall, a prática intelectual dos EC volta-se para seu maior problema, a institucionalização, ou seja, para a reflexão sobre sua própria posição institucional. Daí ser tão caras aos EC britânicos a noção de intelectual orgânico gramsciana - como direcionadora de sua postura política - e a noção de cultura enquanto texto de Raymond Williams $(2000$; 2007) - para apreender "suas outras formações, da intertextualidade dos textos como fontes de poder, da textualidade como local de representação e de resistência". Se

"nunca foi possível no campo teórico dos estudos culturais [...] dar conta das relações da cultura e dos seus efeitos", é preciso assumir as tensões, "manter questões políticas e teóricas numa tensão não resolvida e permanente. Os estudos culturais permitem que essas questões se irritem, se perturbem e se incomodem reciprocamente, sem insistir numa clausura teórica final" - "isso define os estudos culturais como projeto" (HALL, 2003: 215-218).

No caso do Pós-Crítica, a partir de sua apresentação, entendemos que sua crítica se faz a partir do seu campo de pesquisa e de investigação, ou talvez, de intervenção:

[O Pós-Crítica] Abrange a produção de autores considerados menores, além do consumo e distribuição de textos entre comunidades destituídas de acesso a bens culturais e seus modos de produção. No limite, além das representações derivadas da obra de arte, problematizando as relações entre local e global, são os modos de vida como práticas sociais e estéticas contra-hegemônicas que constituem o amplo espectro das investigações.

Então, considerando que o próprio programa coloca em sua apresentação as "estéticas contra-hegemônicas" como seu campo de investigação e o nome de Stuart Hall como um ponto referencial, como apontar uma teoria do método para o Pós-Crítica? O que se segue são apontamentos para uma direção na busca de um método em crítica cultural considerando a região de Alagoinhas como campo de atuação, ou seja: como deslocar e/ou se apropriar do pensamento de Stuart Hall inserindo-o no contexto do Litoral Norte e Agreste da Bahia e, consequentemente, que questões levantar ao implicar investigações de crítica cultural nesse território. Estes apontamentos partem da 
experiência do curso do componente curricular Metodologia da Pesquisa em Crítica Cultural (2010.1) do Pós-Crítica, ministrado pelo coordenador do programa, Prof. Dr. Osmar Moreira, e pela Prof. Dr. Eliana C. B. Gonçalves.

\section{Um pesquisador de crítica cultural em campo}

Uma vez sabido qual o "amplo espectro das investigações" do Pós-Crítica, o próximo passo é buscar um paradigma de atuação científica e institucional para o pesquisador. Já foi mencionada, indiretamente através de Stuart Hall, a sombra do intelectual orgânico gramsciano como modelo de atuação intelectual. Nesse sentido, precisam-se reconhecer movimentos sociais emergentes e seus respectivos intelectuais orgânicos - líderes, formadores de opinião, mediadores e/ou representantes comunitários, presidentes de associações, mobilizadores culturais, etc. - possíveis de relações concretas com o Pós-Crítica: Casa do Poeta de Alagoinhas, Associação dos Moradores de Alagoinhas, Fundação Iraci Gama, Central dos Agricultores do Litoral Norte/BA, entre tantas cooperativas, grupos de mulheres, etc. Se estes grupos, entre tantos outros, são os referentes do "amplo espectro das investigações" do Pós-Crítica e se existe uma noção gramsciana da atividade intelectual, que posicionamento político e institucional apontar para o crítico cultural atuando na região de Alagoinhas?

O primeiro nome a ser discutido no referido curso foi o francês René Barbier (2004), sociólogo da educação. O título escolhido não poderia ser outro, trata-se de seu A pesquisa-ação, no qual o autor expõe um modelo nada tradicional de pesquisa em sociologia (voltado para a educação) que pode ser adaptado numa espécie de sociologia da cultura. Barbier defende um programa totalmente revolucionário para a pesquisa com grupos sociais, no qual a própria pesquisa é traçada em parceria com o grupo-alvo, ou na linguagem do autor, com o grupo-sujeito ou sujeito coletivo. O pesquisador assume um papel de organizador, coordenador e executor da pesquisa e seus resultados são esperados de forma decisiva no processo em que se insere o objeto - observa-se que a velha discussão axiológica em relação à observação participante da crítica social é ultrapassada no método de Barbier, a pesquisa-ação está intimamente ligada ao seu objeto e se insere no campo exatamente como ação transformadora. 
A pesquisa-ação obriga o pesquisador de implicar-se. Ele percebe como está implicado pela estrutura social na qual ele está inserido e pelo jogo de desejos e de interesses de outros. [...]. Ele compreende, então, que as ciências humanas são, essencialmente, ciências de interações entre sujeito e objeto de pesquisa. $\mathrm{O}$ pesquisador realiza que sua própria vida social e afetiva está presente na pesquisa sociológica [...]. O pesquisador descobre que na pesquisa-ação, que eu denomino de pesquisa-ação existencial, não se trabalha sobre os outros, mas e sempre com os outros. Ele não apresenta sozinho seu relatório de pesquisa ao solicitante da pesquisa [...], sem antes o ter apresentado ao seu grupo de pesquisa de campo, principal interessado (BARBIER, 2004: 14-15).

Para tanto, o autor defende um tipo de interdisciplinaridade para além de como essa questão é pensada e proposta nos EC brasileiros e propõe uma "abordagem transversal" multirreferenciada - que corresponde à teoria da qual a pesquisa-ação é sua "metodologia específica". Essa abordagem entende que o sujeito-objeto é composto de três dimensões: a pessoal (pulsões e desejos), a social (que se impõe sobre o sujeito) e a sacral (representações míticas e mitológicas preconcebidas sobre o objeto). Para Barbier a limitação da ciência ocidental parte justamente da falsa interdisciplinaridade - falsa porque não incide sobre o corpus científico de maneira verdadeiramente radical, isto é, não permite que outros discursos para além deste corpus sejam também referenciados e incorporados nessa interdisciplinaridade: esta é a causa do fato de a ciência ocidental não conseguir uma interpretação interativa de determinados objetos. Seria este o posicionamento do crítico cultural enquanto pesquisador nas margens do subdesenvolvimento, nas grades do capitalismo neoliberal de políticas provincianas e paternalistas, uma vez que o pesquisador em pesquisa-ação "No decorrer de sua prática, ele é às vezes sociólogo, ou psicossociólogo, ou filósofo, ou inventor, ou militante, etc." (Idem, p. 18).

\section{Delimitando objetos de pesquisa a partir da noção de arquivo}

Nesse contexto, torna-se incontável o número de possibilidades de problemas locais que podem se transformar em objetos de pesquisa para o programa - depende em muito da criatividade e da afetividade de cada proponente. Nesse campo, é imprescindível vencer uma barreira presente em vários interiores brasileiros: a existência de dados, fontes e arquivos disponíveis à pesquisa. A questão material não 
pode ser negligenciada e nem será resolvida com um simples gesto de boa vontade de programas de pós-graduação, é preciso que o poder público organize, em cada cidade, um arquivo público preparado a visitações acadêmicas e disponibilize arquivos e dados que haja em repartições públicas.

No entanto, os EC em muito se limitariam se delimitassem objetos com base apenas nessa noção tradicional de arquivo. Por isso Mal de arquivo de Jacques Derrida (2001a) é referência obrigatória para o curso de Metodologia da Pesquisa em Crítica Cultural do Pós-Crítica. O autor expande o arquivo para além da busca do tempo perdido através da memória e da arqueologia coletivas; defende que todo arquivo pressupõe marcas, impressões, inscrições bem como técnicas de armazenamento, repetição e decodificação desses dados - todo arquivo é um conjunto vivo com suas peculiaridades e características próprias. Sua leitura foi introduzida pelo texto de Leonor Archuf (2008) La autobiografia como (mal de) archivo, que, a partir de Derrida, traz a noção de arquivo para a memória, a subjetividade e as narrativas individuais. Doravante, os problemas de silenciamento, exclusão, estereotipização, se traduzem em objetos mil, desde memórias de anciãos ribeirinhos às práticas de cineastas amadores, uma vez que os arquivos que darão suporte à investigação de alguns entre esses sujeitos-objetos podem se encerrar neles próprios através de suas narrativas, testemunhos e autobiografias.

\section{Um método de investigação do sujeito-objeto}

Chegamos a algumas contribuições próprias da disciplina histórica: o paradigma indiciário proposto pelo historiador italiano Carlo Ginzburg (1990) como um método de investigar objetos concretos e/ou ocultados através da análise de elementos não percebidos, "pormenores mais negligenciáveis", "normalmente considerados sem importância, ou até triviais". Trata-se, nas palavras de Ginzburg, de um método devedor “da semiótica médica: a disciplina que permite diagnosticar as doenças inacessíveis à observação direta na base de sintomas superficiais, às vezes irrelevantes aos olhos do leigo" (GINZBURG, 1990: 151). O paradigma indiciário traz consigo uma questão metodológica de suma importância para os EC: 
ou sacrificar o conhecimento do elemento individual à generalização (mais ou menos rigorosa, mais ou menos formulável em linguagem matemática), ou procurar elaborar, talvez às apalpadelas, um paradigma diferente, fundado no conhecimento científico (mas de toda uma cientificidade ainda por se definir) do individual (Idem, p. 163).

É evidente, depois de tudo o que aqui já foi dito, que os EC são, justamente, uma possibilidade teórica de traduzir tudo aquilo que até então fora sacrificado, assim como o individual. Para além disso, Ginzburg nos lembra ainda a questão axiológica oriunda das ciências naturais que orienta ao pesquisador a máxima distância afetiva entre ele e seu objeto, numa equação em que "A tendência a apagar os traços individuais de um objeto é diretamente proporcional à distância emocional do observador" (GINZBURG, 1990: 163). Por questões de natureza mesma de cada objeto - de um lado a cultura, e de outro a natureza - torna-se óbvio que os EC requerem métodos diferentes. E, para Ginzburg, o paradigma indiciário pode servir como instrumento tanto para "elaborar formas de controle social" eficaz - ao prestigiar os detalhes individuais - como para “dissolver as névoas da ideologia que, cada vez mais, obscurecem uma estrutura social como a do capitalismo maduro" (Idem, p. 177). Para o historiador italiano, em nome de um mínimo de rigor científico, a ideia de totalidade não deve ser abandonada, uma vez que os indícios são sinais exatamente de algo nebuloso que abarca as conexões entre os próprios indícios: "Se a realidade é opaca, existem zonas privilegiadas - sinais, indícios - que permitem decifrá-la" (Idem, ibidem). Se o pensamento sistemático sai de cena, dá lugar ao pensamento aforismático:

O próprio termo 'aforismático' é revelador. (É um indício, um sintoma, um sinal: do paradigma não se escapa.) Com efeito, Aforismos era o título de uma famosa obra de Hipócrates. No século XVII, começaram a sair coletâneas de Aforismos políticos. A literatura aforismática é, por definição, uma tentativa de formular juízos sobre o homem e a sociedade a partir de sintomas, de indícios: um homem e uma sociedade que estão doentes, em crise. E também "crise" é um termo médico, hipocrático (Idem, p. 178).

Mas Ginzburg volta ao problema que a ala da comunidade científica mais tradicional não deixa esquecer: "pode um paradigma indiciário ser rigoroso?”. Agora, não mais usando os termos "individual" e "generalização" como uma falsa antagonia, o problema central é trazido diretamente: "ou assumir um estatuto científico frágil para chegar a resultados relevantes, ou assumir um estatuto científico forte para chegar a 
resultados de pouca relevância" - e mais uma vez a escolha já é induzida no próprio enunciado, visto que tratamos de um projeto sério e político com olhos a intervenções por demais relevantes. Como propõe Sartre (2002; ver nota 3), o conhecimento que podemos ter como Saber do contemporâneo é de tipo objetivo, não podendo traduzir em si fenômenos subjetivos. Para Ginzburg, "este tipo de rigor é não só inatingível mas também indesejável para as formas de saber mais ligadas à experiência cotidiana" (GINZBURG, 1990: 178).

Se levarmos em consideração que, na relação dos EC britânicos com o marxismo narrada por Stuart Hall (2003), os primeiros estabeleceram para si objetos que até então estiveram além da abordagem marxista, tais como "cultura, ideologia, linguagem, o simbólico", além de outros como as questões sexuais e de gênero e raciais, o desejo, etc., então estamos pensando uma semiologia da cultura que, através de uma teoria do método de rigor flexível, se debruce sobre elementos socioculturais pouco notados que apontem para uma realidade regional relacionada aos agouros da globalização contemporânea. Um debruçamento implicado. Em outras palavras, falamos de uma proposta para os estudos investigativos do Pós-Crítica: “a proposta de um método interpretativo centrado sobre os resíduos, sobre os dados marginais, considerados reveladores" (GINZBURG, 1990: 149).

\section{Crítica cultural como gramatologia}

Tragamos a situação para questões de ordem muito práticas a um pesquisador do Pós-Crítica: imagina-se certa atitude implicada do pesquisador, (e daí) uma eleição e uma abordagem diferenciadas dos objetos, mas o trabalho de materializar os resultados obtidos exige, por sua vez, um processo também complexo, porque estratégico, e não pode ser negligenciado. Na perspectiva de pesquisa aqui apresentada, são dois os tipos de resultados: a dissertação e as consequências da pesquisa para o sujeito-objeto delimitado.

É assim que o pensamento de Derrida sobre a escrita traz as contribuições de sua desconstrução enquanto crítica, da impressão da différance como estratégia e economia geral da desconstrução, estratégia que deve "evitar simplesmente neutralizar as oposições binárias da metafísica e, ao mesmo tempo, simplesmente residir, no campo fechado dessas oposições e, portanto, confirmá-lo" (DERRIDA, 2001b: 47). As 
oposições, para Derrida, não se encontram num "face a face", mas em situação de "hierarquia violenta", de comando de um elemento sobre o outro. "Desconstruir a oposição significa, primeiramente, em um momento dado, inverter a hierarquia" (Idem, p. 48). Em linhas gerais, a desconstrução derridiana opera em duas fases: primeiro, a inversão -

Descuidar-se dessa fase de inversão significa esquecer a estrutura conflitiva e subordinante da oposição. Significa, pois, passar muito rapidamente [...] a uma neutralização que, praticamente, deixaria intacto o campo anterior, privando-se de todos os meios de aí intervir efetivamente (Idem, ibidem)

-, em seguida, "operar no terreno e no interior do sistema desconstruído". O resultado de uma operação de desconstrução deve ser sempre "a emergência de um novo 'conceito', um conceito que não se deixa mais - que nunca se deixou - compreender no regime anterior", um conceito que nunca se constitui no "terceiro termo", em "uma solução na forma da dialética especulativa" hegeliana (DERRIDA, 2001b: 48-49). O esforço de Derrida é evitar a suprassunção dialética hegeliana, na qual a contradição se faz pela neutralização e negação do elemento primeiro sem nele intervir.

A desconstrução torna-se, assim, uma crítica ao idealismo hegeliano e, portanto, ao logocentrismo. Não é simplesmente a inversão, mas, ao mesmo tempo, a demarcação e a vigilância das unidades da tradição idealista, no sentido de evitar que sejam reapropriadas. Destarte, a noção de materialismo não se coloca como um simples substituto ao idealismo, mas como seu duplo, como a marca da diferença, uma escrita intersticial que afirma os elementos binários e neles opera concretamente sem horizontes de origens comuns e de sentido unitário. É preciso, contudo, não incorrer, nos alerta Derrida, no uso metafísico do termo "matéria", como um "significado transcendental" que explica em termos absolutos somente o exterior, o sensível e a presença - um materialismo do interior, do ideal e da ausência, o "espírito" ou "consciência" "como uma das formas da matéria", eis a inversão em termos de cartografia de crítica cultural.

Na tradição idealista, metafísica, a escrita tem papel secundário, uma vez que ela seria uma tentativa de expressar secundariamente a principal "substância significante" do "conceito significado", a phoné. A escrita deve ter um gesto duplo: marcar a si 
mesma ao mesmo tempo em que (de)marca a phoné, ser o próprio signo, o espaçamento entre uma e outra, e não um elemento opositor. Esta seria uma operação materialista da escrita, pois "A redução da escrita - como redução da exterioridade do significante - ia de mãos dadas com o fonologismo e o logocentrismo" (DERRIDA, 2001c: 30). A escrita como desconstrução, portanto, opõe-se a um tipo de escrita representativa, fonético-alfabético, que se apaga frente ao objeto representado, a fala, uma escrita logocêntrica e etnocêntrica. Este novo conceito de escrita é, em Derrida, a própria différance, a grama, a gramatologia, "uma produção sistemática de diferenças, a produção de um sistema de diferenças". Uma escrita dupla que, ao mesmo tempo, inverta a hierarquia fala/escrita e exploda "uma escrita no próprio interior da fala", desorganizando o logocentrismo, uma escrita suplementar, pois que "o suplemento não é nem um mais nem um menos, nem um fora nem um complemento de um dentro, nem um acidente nem uma essência" (DERRIDA, 2001b: 50). Se a escrita é um jogo de diferenças, um texto, ela não implica a negação da expressão, pois "os elementos se remetem uns aos outros" e o "devir-espaço" entre tais diferenças é a produção mesma sem a qual as diferenças "não significariam, não funcionariam". Uma diferença não pode funcionar, como signo, sem se remeter a outra diferença, ou seja, cada elemento, seja na ordem do discurso escrito ou falado, constitui-se a partir do rastro, "que existe nele, dos outros elementos da cadeia ou do sistema": um texto só se produz na transformação de outro texto, uma escrita não se produz senão na transformação da fala e não como sua mera representação - basta localizar o discurso cultural hegemônico em sua posição superior e explodir uma escrita dupla no seu próprio interior, em suas próprias insuficiências e lacunas.

Se a história da filosofia ocidental é marcada por uma negligência da escrita, ela é posta, por essa mesma filosofia, no mesmo patamar que é colocado o mito. A filosofia como suprema expressão da razão entende que a phoné está mais próxima da Verdade do que sua mera representação, a grafia. A este movimento Derrida chama de o "rebaixamento da escrita", sua representação e localização na hierarquia filosófica. A gramatologia desconstruirá a oposição entre logos e mythos, é uma investida materialista no seio da tradição idealista, uma escrita transformativa, escrita-práxis: inversão da hierarquia theoria/práxis, relação do texto com seu "lado de fora", com sua realidade. A gramatologia, a desconstrução, torna-se um projeto, um discurso, uma 
crítica teórica, portanto, "se ele deve se articular rigorosamente com uma prática mais geral, é preciso que ela tenha em conta a mais potente formação discursiva, a mais extensa, a mais durável, a mais sistemática de nossa 'cultura" (DERRIDA, 2001b: 102).

O posicionamento político-filosófico da crítica cultural em relação ao Saber contemporâneo

Voltando a René Barbier, nos encontramos com a segunda ordem de resultados avistados para uma pesquisa do crítico cultural que devem ser pensados intrinsecamente com a dissertação: trata-se da ação transformadora da realidade. E ao falar em realidade voltamos à questão da adoção de um modelo filosófico ao mesmo tempo investigativo e transformador, da necessidade de se ter tal modelo. É mesmo possível abrir mão de um tal modelo quando se elabora intervenções políticas estratégicas na sociedade?

Antes de qualquer coisa, retomemos o que Stuart Hall fala sobre a relação dos EC britânicos com o marxismo. A própria Nova Esquerda britânica (que representa um ponto de crise e, por isso, de ampliação fundamental do marxismo) é quem traz as primeiras questões da agenda dos EC; nesse primeiro momento, segundo Hall, os EC não apresentavam problemas novos:

o poder, a extensão global e as capacidades de realização histórica do capital; a questão de classe social; os relacionamentos complexos entre o poder [...] e a exploração; a questão de uma teoria que poderia ligar, sob uma reflexão crítica, os domínios distintos da vida, a política e a teoria, a teoria e a prática, questões econômicas, políticas, ideológicas, e assim por diante; a própria noção de conhecimento crítico e sua produção como prática (HALL, 2003: 202-203).

Está claro que estas questões ainda são pauta nos EC, principalmente quando sua gestação se faz nas margens do capitalismo neoliberal. Entretanto, os EC não são uma filosofia do economicus, e o materialismo histórico dialético lhe serve como modelo de investigação da realidade e não como clausura determinante. Por isso, há elementos que aprisionam o marxismo, silêncios retumbantes frutos de evasões e insuficiências teóricas, que os EC encaram - somente com um rigor científico flexível é possível tratar 
problemas que só a partir da década de 1950 tornaram-se inegáveis: o inconsciente, o desejo, gênero e sexualidade, questões etno-raciais, etc.

É preciso, também, esclarecer que o marxismo propriamente dito não é "a" filosofia de investigação e transformação do mundo, mas uma escola, uma disciplina, um campo fechado sobre uma dada filosofia, a saber, o materialismo histórico-dialético de Karl Marx. E, com exceção de seu prognóstico adivinhatório do futuro e vontade de verdade a-histórica, é com ele que os EC buscam operadores teóricos da realidade, entendendo que suas condições históricas de surgimento ainda não foram superadas, apenas transformadas.

Para o crítico estadunidense Fredrich Jameson (2004) há sempre uma desconfiança no êxito de alcance interpretativo de um sistema porque isso acaba por desamparar o sujeito:

Na medida, então, em que o teórico ganha ao construir uma máquina cada vez mais fechada e aterradora, na mesma medida perde, uma vez que a capacidade crítica de seu trabalho fica assim neutralizada, e os impulsos de revolta e de negação, para não falar dos de transformação social, são percebidos, cada vez mais, como gestos inúteis e triviais no enfretamento do modelo proposto (JAMESON, 2004: 31).

Fica claro, então, que a homogeneidade totalizante de um modelo interpretativo da realidade é impossível. A tarefa seria, assim, buscar brechas, espaçamentos, zonas opacas que o "sistema" proposto não consegue dobrar para si. Somente dessa forma podemos ensaiar gestos transformadores, possíveis de alternativas que não podem ser dominadas. É nesse sentido que Jameson acredita não ser o pós-modernismo uma realidade negativa aterradora e nem a modernidade uma realidade superada por completo. É preciso que os indícios apontem para algo que buscamos conferir a fim de nos posicionarmos: "Se não chegarmos a uma idéia geral de uma dominante cultural, teremos que voltar à visão da história do presente como pura heterogeneidade, como diferença aleatória, como a coexistência de forças cuja efetividade é impossível aferir" (JAMESON, 2004: 31-32) - o modelo como salvaguarda de um sentido para o contemporâneo. O presente como compreensão da realidade torna-se, para desespero dos deterministas, uma conjectura e nossas ações transformadoras são ações sobre um presente conjecturado. E se estivermos equivocados? Então a história provará que 
nossas ações foram equivocadas. A conjectura de Jameson é que o presente é uma terceira forma do capitalismo apontada pelo belga Ernest Mandel (1982), o capitalismo tardio, caracterizado pela tecnologia nuclear e a nascente microeletrônica, pelo capital financeiro e pelo modelo socioeconômico do welfare state - no qual Jameson localiza, como principal mudança em relação à modernidade, a agroindústria (representando a extinção dos campesinatos tradicionais), de um lado, e a indústria cultural com a cultura de massas (representando a dissolução da fronteira entre cultura erudita e cultura popular, o que põe a "produção estética", da arte e da cultura, numa nova posição socioeconômica: "integrada à produção das mercadorias em geral") de outro (JAMESON, 2001). É a esta conjectura que o Pós-Crítica se alia ao delimitar "práticas sociais e estéticas contra-hegemônicas" como os indícios que suas pesquisas investigarão - e um ponto problemático é qual método adotar para essa investigação.

Outra defesa de um modelo filosófico como norte para uma atitude de negação ativa e positiva contra "o sistema" (sistema esse com fissuras e insuficiências, é claro) encontramos em Sartre (2002) e em Lukács (2003). Sartre concorda com Marx em que as ideias dominantes de uma época são as ideias do grupo/classe dominante, e sendo que uma "filosofia se constitui para dar expressão ao movimento geral da sociedade", para servir "de meio cultural aos contemporâneos", ela é apresentada "como a totalização do Saber contemporâneo" - sua eficácia é medida em termos de performance e hegemonia na tradução da realidade presente. A ideologia burguesa capitalista seria a tentativa, ao atrelar-se à metafísica idealista hegeliana, de imagem da realidade e orientadora dos atos do sujeito nessa realidade. Já o filósofo húngaro apresenta a dialética marxiana como uma "dialética revolucionária" justamente por ser um pensamento de inversão, ao colocar "a relação dialética do sujeito e do objeto no processo da história" como o problema central "das considerações metodológicas":

Ora, privado dessa determinação, o método dialético [...] deixa de ser um método revolucionário. A diferença em relação à "metafísica" não é mais procurada no fato de que em todo estudo "metafísico" o objeto de estudo deve permanecer intocado e imodificado e que, por conseguinte, o estudo permanece numa perspectiva puramente contemplativa, sem se tornar prático, enquanto para o método dialético a transformação da realidade constitui o problema central (LUKÁCS, 2003: 67-68). 
Dessa forma, o "concreto" não será mais a síntese, o resultado, mas "o ponto de partida real e também, por conseguinte, o ponto da intuição e da representação" (Idem, p. 77). Este modelo de explicação e investigação da realidade, proposto por Marx, é, para Sartre, uma do limitadíssimo conjunto de apenas três filosofias criadas entre os séculos XVII e XX, considerando "que uma filosofia, quando está em sua plena virulência, nunca se apresenta como uma coisa inerte, como a unidade passiva e já terminada do Saber; nascida do movimento social, ela própria é movimento e age sobre o futuro" (SARTRE, 2002: 20-21). Ou seja, ao mesmo tempo em que se inverte a dialética metafísica inserindo no jogo o elemento matéria como ponto de partida, apresenta-se um método para essa filosofia que parte de outra experiência do "concreto" que não é a burguesa, ao contrário, o ponto de partida é a experiência proletária, pois, "a confiança que [uma filosofia] tem em si mesma e em seu desenvolvimento futuro limita-se a reproduzir as certezas da classe que a sustentam" (Idem, ibidem), ou, em outras palavras, de continuar investigando indícios, rastros, conjecturas, que apontem para essas certezas.

Verifica-se em maior grau a revolução causada pela dialética marxiana quando notamos que a inversão é total: não é mais a burguesia que veicula uma ideia, e sim o proletariado:

quando ele se apresentava como uma determinação real do proletariado, como o sentido profundo - para si mesmo e em - de seus atos, tal pensamento nos atraía [trata-se do grupo de universitários "classe média" ao qual o autor fazia parte] de forma irresistível sem que o soubéssemos e deformava toda nossa cultura adquirida. Vou repetir: não era a idéia que nos perturbava; também não era a condição operária, da qual tínhamos um conhecimento abstrato, mas não a experiência. Não: era uma coisa ligada à outra, era [...] o proletariado como encarnação e veículo de uma idéia (Idem, p. 28-29).

São as massas como parte constitutiva da própria filosofia, a prática como parte constitutiva da teoria. A crise do marxismo, para Sartre, se explica pelo fato de lhe causarem uma cisão interna entre elementos que são intrínsecos: a teoria e a prática, os intelectuais e os operários, a experiência e a reflexão, o inteligível e o sensível, o transcendente e o empírico (vencendo sempre, no idealismo, o primeiro termo) - é este, para o autor, o "devir-mundo da filosofia" marxiana. É, também, por esta razão que os EC têm muito bem definidos pontos de choque com o marxismo: 
"a ortodoxia, o caráter doutrinário, o determinismo, o reducionismo, a imutável lei da história, o seu estatuto como metanarrativa", "um certo reducionismo e economicismo [...] intrínseco ao marxismo; a contestação do modelo de base e superestrutura, através do qual ambos os marxismos, o sofisticado e o vulgar, tentaram pensar o relacionamento entre sociedade, economia e cultura" (HALL, 2003:203-204).

Em termos de pesquisa em crítica cultural na região de Alagoinhas, trata-se de localizar manifestações culturais contra-hegemônicas, que são alternativas à lógica cultural dominante, que operam em suas brechas, invertem seus símbolos de dominação, imprimem uma dupla cena através de um gesto duplo: artesãos cooperados na reciclagem de embalagens de mercadorias do capitalismo consumista, a sobrevivência do sistema de numeração indígena no seio do ensino formal na aldeia, as novas linguagens informáticas de jovens conectados em redes virtuais, a história de atores excluídos através de discursos da elite, a procura de indícios marginalizados pela literatura oficial no interior de romances canonizados, memórias de anciãos ribeirinhos como retomada de modos de vida contra-hegemônicos, novas literaturas porque novos canais de veiculação e novas formas de leitura, redes de teatro "amador", presenças de manifestações socioculturais populares nos currículos da educação formal como prática de letramento, a aparição de práticas sexuais censuradas na literatura comercial e na canônica, as formas autodidatas de artistas amadores de criarem produtos com outra lógica de produção a partir do consumo de bens culturais da indústria cultural - apenas alguns exemplos de um primeiro exercício de cartografia dessas manifestações que, ao mesmo tempo em que marcam a si mesmas, demarcam a lógica cultural do capitalismo tardio nas margens do interior baiano.

O exercício do crítico cultural em Alagoinhas, ao mesmo tempo em que demarca as formas globais de hegemonia e homogeneização, um tipo de Saber contemporâneo que prega o continuísmo das posições de quem produz a riqueza das nações e de quem privatiza seus resultados em capital, marca sua posição ao passo que investiga os indícios de uma realidade a qual ele percebe de forma implicada. A crítica cultural herdeira dos EC na região de Alagoinhas, o Pós-Crítica, adotando um materialismo pósmarxista como filosofia que lhe oferece um sentido para o contemporâneo contemporâneo marcado pelo que concordamos como o capitalismo tardio -, enxergando aí concretamente o problema da exclusão do idealismo hegeliano, deve, 
portanto, investigar, de forma implicada, os rastros, os indícios, os sintomas, de uma hipotética realidade - elementos estes que sejam, por sua vez, também, eles próprios, a dobra dessa realidade, seu inverso, a différance. Seu método? Então, se respondemos "a desconstrução indiciária", estaríamos concluindo os componentes necessários a uma ciência? Seria a Crítica Cultural agora uma ciência? Somente na condição de um "rigor flexível", de possuir "um estatuto científico frágil" e um campo multidisciplinar e de uma nova forma de experimentar a Universidade.

\section{REFERÊNCIAS}

ARFUCH, Leonor. La autobiografia como (mal de) archivo In: Crítica cultural entre política y poética. Argentina: Fondo de Cultura Economica de España, 2008.

BARBIER, René. A pesquisa-ação. Trad. Lucie Didio. Brasília: Líber Livro Editora, 2004.

CANCLINI, Néstor Garcia. Culturas híbridas: estratégias para entrar e sair da modernidade. 3 ed. Trad. Ana Regina Lessa e Heloísa Pezza Cintrão. São Paulo: EDUSP, 2000.

DERRIDA, Jacques. Mal de arquivo: uma impressão freudiana. Trad. Claudia de Moraes Rego. Rio de Janeiro: Relume Dumará, 2001.

DERRIDA, Jacques. Posições In: Posições. Trad. Tomaz Tadeu da Silva. Belo Horizonte: Autêntica, 2001.

DERRIDA, Jacques. Semiologia e gramatologia (Entrevista a Julia Kristeva) In: Posições. Trad. Tomaz Tadeu da Silva. Belo Horizonte: Autêntica, 2001.

GINZBURG, Carlo. Sinais: raízes de um paradigma indiciário In: Mitos, emblemas, sinais: morfologia e história. São Paulo: Companhia das Letras, 1990.

GRAMSCI, Antonio. Os intelectuais e a organização da Cultura. Trad. Carlos Nelson Coutinho. 8 ed. Rio de Janeiro: Civilização Brasileira, 1991.

GUATTARI, Félix. As três ecologias. 15. ed. Campinas: Papirus, 2004.

HALL, Stuart; SOVIK, Liv. UNESCO. Da Diáspora: identidades e mediações culturais. Trad. Adelaine La Guardia Resende [et al.]. Belo Horizonte: Ed. UFMG; Brasília: Unesco, 2003 (Humanitas). 
HALL, Stuart. A identidade cultural na pós-modernidade. 11 ed. Trad. Tomaz T. da Silva e Guaracira L. Louro. Rio de Janeiro: DP\&A, 2006.

JAMESON. Fredric. Globalização e estratégia política. ln SADER, Emir (org.). Contracorrente: o melhor da New Left Review em 2000. Rio de Janeiro: Record, 2001.

JAMESON. Fredric. Pós-modernismo: a lógica cultural do capitalismo tardio. 2 ed. Trad. Maria Elisa Cevasco. São Paulo: Ática, 2004 (Série Temas, Cultura e sociedade, v. 41).

LUKÁCS, Georg. O que é marxismo ortodoxo? In: História e consciência de classe: estudos sobre dialética marxista. Trad. Rodnei Nascimento. São Paulo: Martins Fontes, 2003.

MANDEL, Ernest. O Capitalismo Tardio. São Paulo: Abril Cultural, 1982.

MARX, Karl. Contribuição à crítica da economia política. 2 ed. São Paulo: Martins Fontes, 1983 (Série novas direções).

MARX, Karl. $O$ capital. 2 ed. Trad. Regis Barbosa e Flávio R. Kothe. São Paulo: Nova Cultural, 1985, v. 1 (Os economistas).

MARX, Karl; ENGELS, Frederich. A ideologia alemã. São Paulo: Martins Fontes, 1989 (Série novas direções).

MARX, Karl. Manuscritos econômico-filosóficos. Trad. Jesus Ranieri. São Paulo: Boitempo, 2004.

SARTRE, Jean-Paul. Marxismo e existencialismo In: Crítica da razão dialética: precedido por Questões de método. Trad. Guilherme João de Freitas Teixeira. Rio de Janeiro: DP\&A, 2002.

WILLIAMS, Raymond. Cultura. 2ª Ed. São Paulo: Paz e Terra, 2000.

WILLIAMS, Raymond. Palavras-chave: um vocabulário de cultura e sociedade. Trad. Sandra Guardini Vasconcelos. São Paulo: Boitempo, 2007.

GUATARRI, Félix. As três ecologias. 15 ${ }^{\mathrm{a}}$ Ed. Trad. Maria Cristina F. Bittencourt. Campinas: Papirus, 2004.

WWW.POSCRITICA.UNEB.BR.

RECEBIDO EM: 03 de novembro de 2011

APROVADO EM: 01 de dezembro de 2011 